Research Article

\title{
Simulation Analysis and Scheme Optimization of Energy Consumption in Public Buildings
}

\author{
Yang Liu $\mathbb{D},{ }^{1}$ Shiqing Zou, ${ }^{1}$ Hongyu Chen $\left(\mathbb{D},{ }^{2}\right.$ Xianguo $W u,{ }^{3}$ and Wenman Chen ${ }^{4}$ \\ ${ }^{1}$ Wuhan University, Zhongnan Hospital of Wuhan University, Wuhan 430071, China \\ ${ }^{2}$ Nanyang Technological University, School of Civil and Environmental Engineering, Singapore \\ ${ }^{3}$ Huazhong University of Science \& Technology, School of Civil Engineering \& Mechanics, Wuhan Hubei 430074, China \\ ${ }^{4}$ School of Economics and Management, Wuhan University, Wuhan 430072, China \\ Correspondence should be addressed to Hongyu Chen; hongyu0608@126.com
}

Received 27 November 2018; Accepted 12 May 2019; Published 25 July 2019

Academic Editor: Giosuè Boscato

Copyright ( 2019 Yang Liu et al. This is an open access article distributed under the Creative Commons Attribution License, which permits unrestricted use, distribution, and reproduction in any medium, provided the original work is properly cited.

\begin{abstract}
Under the requirement of energy savings and emission reduction in China, building energy consumption, which occupies a rising proportion of the total energy consumption in society, has become the focus of energy conservation research. Public buildings with a high-energy consumption level have become the most important part of energy conservation research. It is of great practical significance and social value to study energy conservation in large public buildings. In this paper, a large office building is taken as an example. First, a simulation model is constructed by using the energy consumption simulation analysis method, and the reliability of the model is verified by a comparison with the actual energy consumption. Second, based on the model, the thermal design parameters of six building envelope structures, including the external wall heat transfer coefficient, are analyzed in the order of energy-saving sensitivity. Based on the results of the sensitivity analysis, suggestions for each factor are presented. Finally, considering the mutual influence of each parameter on the building energy consumption, the orthogonal design method is used to arrange the test, and the optimal scheme combination of the energy-saving effect is analyzed, which can provide decision support for the energy saving of public building envelopes.
\end{abstract}

\section{Introduction}

By the end of 2017, China's gross domestic product (GDP) has accounted for $15 \%$ of the world's total, but China is the world's largest energy consumer, accounting for $23.2 \%$ of global energy consumption and $33.6 \%$ of global energy consumption growth [1]. Building energy consumption is an important part of China's energy consumption. It is estimated that by 2020 , China's high-energy building area will reach 70 billion square meters, and building energy consumption will reach 108.9 billion tons of standard coal, leading to considerable energy consumption. There are four types of energy consumption categories in the civil buildings in China: heating energy in northern cities and towns, residential energy in cities and towns, residential energy in rural areas, and the energy consumption of public buildings. In terms of energy consumption per unit area and the total energy consumption, the energy consumption of public buildings ranks first among the four types of buildings [2-4]. Public building energy consumption levels in China have been close to those in Europe and the USA. With the economic growth of our country, an individual's requirement for indoor environments and the comfort of buildings has gradually increased. In the future, the energy consumption of public buildings will increase further, which will pose a challenge to national energy security and environmental sustainability. Therefore, controlling and reducing the energy consumption of public buildings is of great significance to controlling the sustainable development of China.

The energy savings of building envelopes and equipment systems and the energy saving between management and behavior in equipment operation and maintenance are the most important sources of energy-saving potential in public buildings $[5,6]$. Buildings exchange heat with the outside through the envelope structure, and the 
performance of the envelope structure determines the amount of heat exchange between the building and the outside, thus affecting the level of building energy consumption. Therefore, improving the performance of a large-scale public building envelope is an effective way to improve the building energy efficiency ratio.

Some studies have achieved better energy efficiency by optimizing the thermal parameters of the enclosure structures. Baran et al. [7] studied the sensitivities of building heating and refrigeration energy consumption, the heat transfer coefficient of the envelope, and design parameters, such as building orientation, depth, story height, and window-wall ratio, in four climate zones in Turkey. Based on the results of the study, suggestions were made for each parameter. Zhou and Zhao [8] used TRNSYS software to simulate the quantitative relationship between the energy consumption of office buildings in five climatic zones and the parameters of different envelopes in China. According to the energy-saving rate index, the influence of seven envelope structure design parameters, such as the heat transfer coefficient of the outer wall in five climatic zones, on building energy consumption was ranked. Shi et al. [9] used DeST's method for building dynamic energy consumption simulations, studied the influence of building envelope thermal performance on the annual energy consumption of underground office buildings, and provided the recommended optimization values for various climate zones in China.

In other studies, energy-saving schemes have been proposed and compared by energy consumption simulation. Melo et al. [10] chose three new types of insulation materials, namely, gypsum, vermiculite, and an ethylenevinyl acetate (EVA) copolymer and compared their use in hot Brazilian areas with traditional envelopes. These authors found that the new materials reduced the thermal load of buildings by $38 \%$. Antonyová et al. [11] developed a nondestructive testing method for insulation walls by measuring the air temperature and humidity inside and outside of the buildings, as well as between the insulation panels and walls. A new instrument for measuring the thermal and humidity characteristics of building envelopes was developed, and the measurement results were analyzed mathematically. Huang et al. [12] considered the influence of factors such as the house orientation, window-to-wall ratio, type of thermal insulation material, and window and determined the optimal design of the enclosure structure transformation scheme through a technical and economic analysis.

The above two types of research provide important guidance for promoting the energy conservation of public building envelopes. However, former research studies regarding actual optimization schemes for building regulation are limited, and in later research, an improvement in building energy efficiency standards has not been achieved. This paper combines the above two research methods. Specifically, the direction and scope of the optimization of the envelope structure parameters through energy consumption simulation is first identified, and then the optimization scheme for promoting the energy savings of the public building envelope structure is presented.
In this paper, first, a simulation model for the energy consumption of public buildings based on the DesignBuilder method is constructed, and the reliability of the model is verified by comparing the American Society of Heating and Air Conditioning Engineers (ASHRAE) Guideline with the actual energy consumption. Second, based on this model, the thermal design parameters of six building envelopes, including the heat transfer coefficient of the external wall, were analyzed in the order of the energy-saving sensitivity. Then, based on the results of the sensitivity analysis, this paper puts forward suggestions of a value for each factor and proposes specific energy-saving retrofit schemes for the factors with high sensitivity, taking into account the mutual influence of various parameters on building energy consumption. Finally, an orthogonal experimental design method is used to arrange the experiment, and the optimal scheme combination of the energy-saving effect is analyzed. The technical roadmap is shown in Figure 1.

\section{Methodology}

2.1. Method of the Building Energy Consumption Analysis. In this paper, the DesignBuilder method is adopted, which is a dynamic calculation method based on the theory of unsteady heat transfer. DesignBuilder consists of graphical interface simulation software specially designed for EnergyPlus [13]. The simulation process can be calculated by using

$$
\begin{aligned}
Q(t)= & \sum_{i=1}^{n} S_{i} h_{i}\left[T_{i}(t)-T_{\mathrm{R}}(t)\right]+m(t) C_{\mathrm{p}}\left[T_{\mathrm{O}}(t)-T_{\mathrm{R}}(t)\right] \\
& +Q_{\mathrm{S}}(t),
\end{aligned}
$$

where $Q(t)$ is the cooling load at $t$ time; $S_{i}$ is the area of the first $i$ surface; $h_{i}$ is the heat transfer coefficient on the I surface, $\mathrm{kW} /$ $\left(\mathrm{m}^{2} \cdot{ }^{\circ} \mathrm{C}\right) ; T_{i}(t)$ is the temperature of the inner surface of $i ; T_{\mathrm{R}}(t)$ is the outdoor temperature; $m(t)$ is the fresh air volume at $t$ time, $\mathrm{m}^{3} / \mathrm{s} ; T_{\mathrm{O}}(t)$ is the fresh air temperature; and $Q_{\mathrm{S}}(t)$ is the indoor heat source heat at $t$ time.

The theoretical basis of DesignBuilder is the law of conservation of energy, which considers the process of energy transfer in building heat exchange. In calculating the energy consumption, this approach considers the influence of many external conditions, such as meteorological conditions, the thermal insulation performance of the enclosure structure, the operation of internal equipment, and personnel activities.

\subsection{A Subsection Verification Method for the Energy Con-} sumption Simulation Model. Verification is an important step in modeling. At present, a widely used verification method is to determine whether the simulation results are accurate by setting the threshold of the average deviation of the simulation according to the judgment conditions proposed by the professional norms. By comparing the size relationship between the average deviation and the threshold value, the model can be verified [14]. 


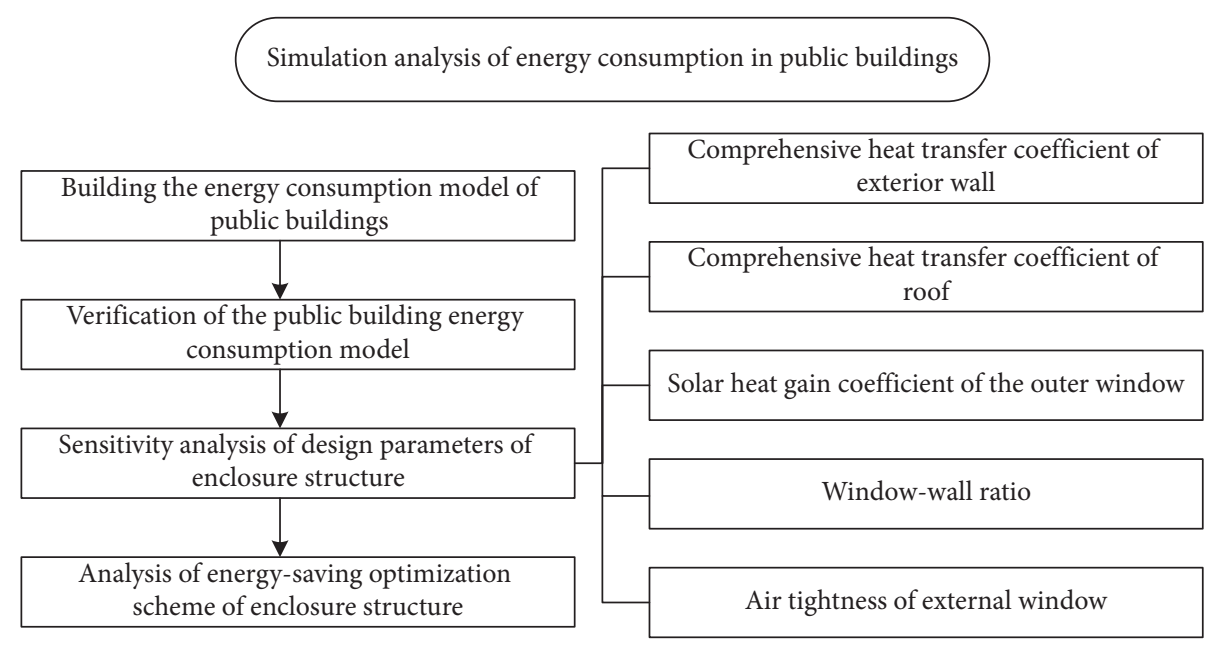

Figure 1: Technical roadmap.

To determine the energy savings of the energy-saving project, the ASHRAE Guideline 14-2002, based on the whole building calibration simulation method, is adopted in this paper. The objective of the method is to establish the building model prior to the energy-saving transformation of the computer simulation. Then, to verify the model, the simulation result is compared with the energy consumption data during the actual operation of the building before the energy-saving renovation. Then, the calibration model is used to predict the energy savings of the energy-saving project.

The error index specified by the ASHRAE Guideline is the standard average deviation (the normalized mean bias error (NMBE) and the coefficient of variation of the root mean square error (CVRMSE)) between the actual energy consumption value and the simulation value. The actual value of the monthly energy consumption of the buildings can be obtained by building an energy consumption bill, and the simulation value of monthly energy consumption can be obtained directly by software simulation. A reliable result of the ASHRAE Guideline indicates the following: $\% \leq \mathrm{NMBE}$ $\leq 5 \%$ and CVRMSE $\leq 15 \%$. This paper compares the calculation results of the NMBE and CVRMSE to determine whether the model can be verified by the ASHRAE Guideline rules. If the model is verified, then the simulation results are close to the actual energy consumption of the building. The model can accurately reflect the actual energy use of buildings and can be used as a basis for further analysis. The formulas for NMBE and CVRMSE are, respectively,

$$
\begin{aligned}
\mathrm{NMBE} & =\frac{\sum_{i=1}^{n}\left(X_{i}-Y\right)}{(n-1) \times \bar{Y}} \times 100, \\
\text { CVRMSE } & =100 \times\left[\frac{\left(\left(\sum_{i=1}^{n}\left(X_{i}-Y_{i}\right)^{2}\right) /(n-1)\right)^{1 / 2}}{\bar{Y}}\right],
\end{aligned}
$$

where $X_{i}\left(Y_{i}\right)$ is the simulation value of the building energy consumption (actual value) in the $i^{\text {th }}$ month and $\bar{Y}$ is the average energy consumption of the buildings.
2.3. Sensitivity Analysis Method. The sensitivity analysis method is a type of data analysis method that quantitatively describes the contribution of the input parameter changes to the output parameter changes. The core of this method is to control the variation in each input variable in the model in the range of its possible values, record the change in the corresponding output variable, and analyze and calculate the influence degree of the input variable on the output variable. In this paper, sensitivity analysis is applied to the energy conservation analysis of the building envelopes. Even if both the parameters unaffected by climate factors and the building use characteristics remain unchanged, only the influence of the design parameter changes in the building envelope on the output variables, such as building energy consumption, is considered to determine its sensitivity to the building energy consumption.

In this paper, formula (4) is chosen as the sensitivity coefficient of the public building energy consumption analysis. The reasons are as follows. First, the comparison between the change percentage of the input and output variables can better highlight the sensitivity; second, the index is dimensionless and can be used for the lateral comparison of the sensitivity between the different types of parameters.

$$
\mathrm{SC}=\frac{\mathrm{OP} \text { change } \%}{\mathrm{IP} \text { change } \%}=\frac{\Delta \mathrm{OP} / \mathrm{OP}}{\Delta \mathrm{IP} / \mathrm{IP}},
$$

where SC is the magnitude of the parameter sensitivity; $\mathrm{OP}$ is the output variable, which represents the building energy consumption; IP is the input variable and represents the thermal design parameters of building envelope; $\Delta \mathrm{OP}$ is the change in the output variable and represents the change in the building energy consumption; and $\Delta \mathrm{IP}$ is the change in input variables and represents the change in the thermal design parameters of the building envelope. The principle of the sensitivity analysis of the building envelope parameters based on the energy consumption simulation is shown in Figure 2.

Based on the above analysis, the sensitivity analysis method of the design parameters of the public building 


\begin{tabular}{|c|c|c|c|c|}
\hline $\begin{array}{c}\text { Input variable } \\
\text { (building enclosure) } \\
\text { design parameters) }\end{array}$ & $\longrightarrow \mathrm{IP}$ & $\begin{array}{c}\text { Energy consumption } \\
\text { simulation model }\end{array}$ & $\begin{array}{c}\text { Output variable } \\
\text { (building energy } \\
\text { consumption) }\end{array}$ \\
\cline { 3 - 4 }
\end{tabular}

FIGURE 2: Principle of the energy-saving sensitivity analysis for the design parameters of the building envelope.

envelope structure is as follows. First, the thermal design parameters of the enclosure structure are selected as input variables, and the energy consumption of the building after the design parameter change is simulated using DesignBuilder software. Then, the sensitivity of building energy consumption to the change in the design parameters is calculated by formula (4). Finally, the sensitivity coefficients of all the parameters are sorted, and the key points of the energy-saving optimization scheme are determined from the design parameters of multiple envelope structures; these factors provide the train of thought and direction for solving the problems.

2.4. Scheme Optimization Method. In scientific research, multifactor and multilevel test designs are often required. Orthogonal experimental design is an efficient method for optimizing multifactor and multilevel problems.

\subsubsection{Design and Realization Method for an Orthogonal} Experiment. Based on probability theory, mathematical statistics, and practical experience, some representative combinatorial design experiments are selected from all levels of combinations of test factors according to the principle of "uniform dispersion, neatness, and comparability." Through the analysis of this part of the representative test results, the influence of the change in the level of each factor on the test results is investigated, and the optimum level of each factor is determined to realize the optimization of the factors.

With the aid of computers, the method of orthogonal design has been widely used. In this paper, an "orthogonal design assistant" is chosen as an auxiliary tool for orthogonal experimental design and analysis. This tool has advantages of small size, convenient installation, simple operation, and fast analysis.

2.4.2. Analysis of the Orthogonal Test Results. On one hand, the change in experimental results is the result of changing experimental conditions; on the other hand, this change is caused by experimental error. Therefore, it is necessary to simultaneously carry out both factor range analysis and variance analysis [16].

(1) Factor Range Analysis. The range of factors refers to the difference between the maximum and the minimum of the average value of the test results (in this paper, the total energy consumption of buildings) at each factor level. This difference reflects the effect of the change in the factor level on the test results. Factor range analysis can clearly and intuitively determine the optimal level of the factors by charts.
(2) Factor Variance Analysis. Factor variance analysis can quantitatively estimate the importance (significance) of the factors to the experimental results. This analysis decomposes the deviations caused by each factor change and the test error and calculates the square sum of the deviation of the factor. Then, by using the hypothesis test method in mathematical statistics, the statistic obeying $F$ distribution is constructed, which is denoted as $F$. These values are then compared with the critical values at a certain significant level (usually 0.05 or 0.01 ). If $F$-value is greater than the critical value, then the influence of factors on the test results is significant at the selected significance level. The reverse is not significant. The analysis of variance (ANOVA) method is as follows:

Taking $x_{k}$ as the result of the $k$ orthogonal test, the total deviation squared $S_{\mathrm{T}}$ and the total freedom $d f_{\mathrm{T}}$ are

$$
\left\{\begin{array}{l}
S_{\mathrm{T}}=\sum_{k=1}^{n} x_{k}^{2}-\frac{1}{n}\left(\sum_{k=1}^{n} x_{k}\right)^{2} \\
d f_{\mathrm{T}}=n-1
\end{array}\right.
$$

The deviation square sum $S_{j}$ and the degree of freedom $d f_{j}$ of the $j$ factor are

$$
\left\{\begin{array}{l}
S_{j}=\frac{1}{n / q} \sum_{i=1}^{q} K_{i j}^{2}-\frac{1}{n}\left(\sum_{k=1}^{n} x_{k}\right)^{2} \\
d f_{j}=q-1
\end{array}\right.
$$

where $K_{i j}$ is the sum of the test results of the $j$ factor at the $i^{\text {th }}$ level.

The error deviation square sum and $S_{\mathrm{e}}$ and the degree of freedom $d f_{\mathrm{e}}$ are

$$
\begin{gathered}
\left\{\begin{array}{l}
S_{\mathrm{e}}=S_{\mathrm{T}}-\sum S_{\mathrm{j}}, \\
d f_{\mathrm{e}}=d f_{\mathrm{T}}-\sum d f_{\mathrm{j}},
\end{array}\right. \\
F-\text { value }=\frac{\text { the factor mean square error }}{\text { the mean square error }} .
\end{gathered}
$$

In the above formulas, the mean square error $=$ the deviation square sum/degree of freedom.

(3) Optimal Scheme Determination. The optimal level of each factor can be preliminarily determined by range analysis, and the significance of each factor can be determined by variance analysis. When choosing the best scheme, the optimal level of the significant factor should be selected, and the nonsignificant factor can be arbitrarily selected. In practice, cost reduction and easy operation are usually considered. The flow chart of energy-saving optimization scheme of building envelope obtained by orthogonal test is shown in Figure 3. 


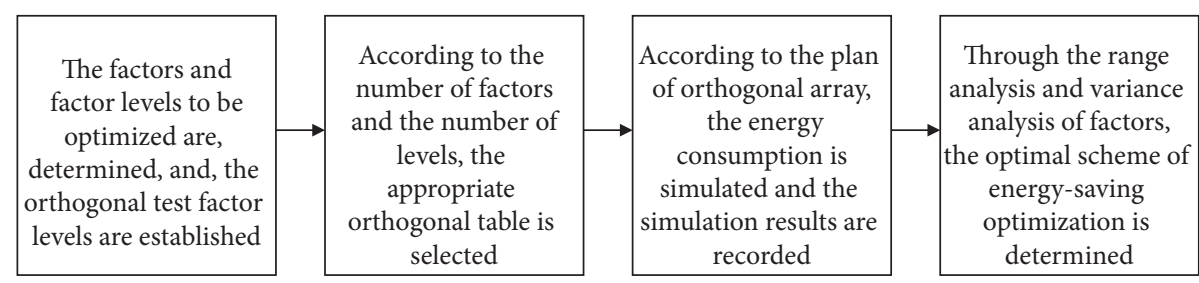

FIgURE 3: Optimization process of the energy-saving scheme of the envelope structure.

\section{Construction of the Energy Consumption Simulation Model for Public Buildings}

In this section, a large commercial office building in the Wuhan area is taken as an example. A simulation model for energy consumption is built, and the annual energy consumption of the building is simulated by DesignBuilder. The reliability of the model is verified by comparing the actual energy consumption with the simulated energy consumption.

\subsection{General Situation and Parameter Setting of Benchmark} Simulation Model. With a total height of approximately 92 meters and 25 floors, the public building covers an area of approximately 1,700 square meters and a total floor area of 34650 square meters. This large-business office building includes office, business, catering, and conference areas. The building shape coefficient is 0.13 , and the ratio of the building's exterior window area to the exterior wall area is 0.3 , which meets the standard regulations for the building shape coefficient of public buildings in hot-summer and cold-winter areas. The main body of the building adopts the frame shear wall structure with no sunshade outside windows. The specific structure of the enclosure is shown in Table 1.

This building is cooled by central air conditioning in the summer and is equipped with three centrifugal chillers (rated power, $340 \mathrm{~kW}$; rated refrigeration capacity, $1758 \mathrm{~kW}$ ) and two central hot water units with a rated heating capacity of $1750 \mathrm{~kW}$ in the winter. In addition, three cold heat pump units (rated refrigerating capacity; $208 \mathrm{~kW}$, rated heat supply, $210 \mathrm{~kW}$ ) are also available for use under the condition of partially opened air conditioning and heating. The office area of the building adopts a fan coil unit plus a fresh air system suitable for the office space, while the other floors adopt a large air duct and a low-speed air supply system. The building has external windows to make full use of the natural ventilation. A structural model based on the above information is shown in Figure 4.

Due to the high-temperature, long-duration summers in the Wuhan region, air conditioning must be turned on for refrigeration. The cooling cycle lasts from late May to late September. The winter climate is wet and cold, and when the temperature is low, the heating system should be turned on, and this cycle usually lasts from mid-December to late February of the following year. The specific operational conditions of the air conditioning and heating system are shown in Table 2.
Different functional areas have different usage characteristics, such as personnel density, lighting density, and equipment density. In this paper, the indoor thermal disturbance is presented in Table 3 through an investigation of building and energy usage. The dynamic change in the personnel density is shown in Figure 5, and the distribution of the equipment utilization rate is similar to that of the personnel density, which is shown in Figure 6 .

In addition, the airtightness of doors and windows also influences the building energy consumption. The number of air exchanges is used to simulate the airtightness of building windows and doors. In the model, the number of air exchanges is set to $0.3 \mathrm{ac} / \mathrm{h}$. The above parameters are input into the established structural model, and a complete simulation model of the building energy consumption is established.

\subsection{Verification and Analysis of the Energy Consumption} Simulation Model. In this section, DesignBuilder is used to carry out a real-time dynamic simulation of the above office buildings throughout the year, and the annual actual energy consumption bill of the buildings is determined. The actual energy consumption value and simulation value of the buildings are obtained, as shown in Table 4 .

3.2.1. Model Verification. According to the energy consumption bill, the total annual energy consumption of the building is $3712.63 \mathrm{MWh}$ per building area and $107.15 \mathrm{kWh} / \mathrm{m}^{2}$ per unit building area. The simulation results show that the annual energy consumption of 3559.52 MWh is $153.11 \mathrm{MWh}$ lower than the actual total energy consumption. The difference between the energy consumption of $102.73 \mathrm{kWh} / \mathrm{m}^{2}$ per unit building area and the actual energy consumption per unit area is $4.42 \mathrm{kWh} / \mathrm{m}^{2}$. Compared with the actual energy consumption, the deviation of the total energy consumption of the simulation is $-4.12 \%$ and the error is relatively small.

The monthly energy consumption simulation value and actual value of the office building are substituted in the simulation model verification method proposed in the second section for verification. Using formulas (2) and (3), the NMBE of this simulation is $-4.50 \%$, the CVRMSE is $6.21 \%$, and the two evaluation indexes are within the range of deviation specified by the ASHRAE Guideline. Therefore, the model can be considered reliable and can be further studied and analyzed. 
TABLE 1: Basic information and construction of the building envelope.

\begin{tabular}{|c|c|c|c|}
\hline Building envelope & Area (square meter) & Construction & $\begin{array}{l}\text { Comprehensive heat transfer } \\
\text { coefficient }\left(\mathrm{W} /\left(\mathrm{m}^{2} \cdot \mathrm{K}\right)\right)\end{array}$ \\
\hline Exterior wall & 15174 & $\begin{array}{c}13 \mathrm{~mm} \text { decorative brick }+20 \mathrm{~mm} \text { lime } \\
\text { mortar }+10 \mathrm{~mm} \text { EPS insulation }+240 \mathrm{~mm} \text { aerated } \\
\text { concrete }+20 \mathrm{~mm} \text { lime mortar }\end{array}$ & 0.50 \\
\hline Roof & 1650 & $\begin{array}{l}40 \mathrm{~mm} \text { C20 fine aggregate concrete }+20 \mathrm{~mm} \text { cement } \\
\text { mortar }+5 \mathrm{~mm} \text { waterproofing membrane }+30 \mathrm{~mm} \\
\text { cement mortar }+60 \mathrm{~mm} \text { EPS insulation }+20 \mathrm{~mm} \\
\text { cement mortar }+120 \mathrm{~mm} \text { reinforced } \\
\text { concrete }+20 \mathrm{~mm} \text { cement mortar }\end{array}$ & 0.35 \\
\hline Exterior window & 5058 & $\begin{array}{l}\text { Aluminum alloy window frame }+6 \mathrm{~mm} \text { net } \\
\text { monochrome glass }\end{array}$ & 6.073 \\
\hline Interior wall & - & $\begin{array}{l}20 \mathrm{~mm} \text { cement mortar }+120 \mathrm{~mm} \text { aerated } \\
\text { concrete }+20 \mathrm{~mm} \text { lime mortar }\end{array}$ & 1.036 \\
\hline Floor & - & $\begin{array}{l}20 \mathrm{~mm} \text { cement mortar }+100 \mathrm{~mm} \text { reinforced } \\
\text { concrete }+20 \mathrm{~mm} \text { cement mortar }\end{array}$ & 2.813 \\
\hline Ground & - & $\begin{array}{l}20 \mathrm{~mm} \text { cement mortar }+80 \mathrm{~mm} \text { fine aggregate } \\
\text { concrete }+500 \mathrm{~mm} \text { compacted clay }\end{array}$ & 0.887 \\
\hline
\end{tabular}

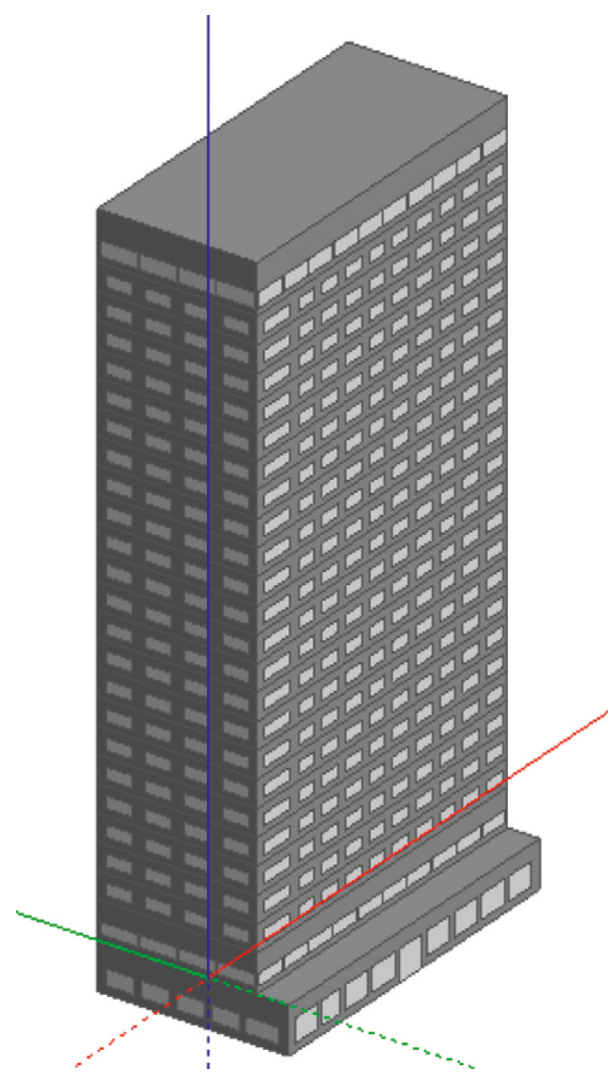

FIGURE 4: Establishment of the benchmark building model.

3.2.2. Analysis of the Model Results. According to the results of Table 3, the simulation curve of building energy consumption is very close to the actual energy consumption curve, and the two curves show the same variation trend. For the Wuhan region, the temperature in January, February, and December is low, and the climate is wet and cold. Thus, the heating and air conditioning system needs to be switched on for a long time, and electricity consumption is higher than that for the remaining months of the year. The weather is hot in the summer months from June to September. Turning on the air conditioning system makes the period more energy intensive. July and August are the hottest periods of the year, and the energy consumption peaks in July. Neither cooling nor heating is required for the remainder of the months, and electricity consumption is significantly lower than that during winter and summer.

The annual energy consumption of buildings is divided into air conditioning, lighting, equipment, and others, and the percentage distribution of energy consumption is drawn, as shown in Figure 7. The energy consumption from the air conditioning system accounts for approximately half of the total energy consumption of the buildings during the whole year.

\section{Energy-Saving Sensitivity Analysis of the Design Parameters of the Public Building Envelope}

The design parameters related to the building energy consumption level mainly include the external wall comprehensive heat transfer coefficient, the roof comprehensive heat transfer coefficient, the outer window solar heat coefficient, the window-to-wall ratio, and the airtightness of the outer window. To comprehensively investigate the energy-saving potential of the design parameters of the envelope structure, this section analyses the energy-saving potential of the design parameters from two aspects, namely, the energy-saving ratio and the parameter sensitivity. The energy-saving ratio is the rate of the difference between the energy consumption of the model and the reference model after the parameter change and the energy consumption of the reference model. This ratio reflects the energy-saving effect of the parameters from the view of the energy-saving amount. The sensitivity coefficient refers to the ratio between the energy consumption change percentage and the parameter change percentage of the model relative to the benchmark model after the parameter changes; this value excludes the influence of dimensions, which is used for 
TABLE 2: System operation during the refrigeration and heating periods.

\begin{tabular}{lccc}
\hline Functional partition & Setting temperature (refrigeration, heating) $\left({ }^{\circ} \mathrm{C}\right)$ & Daily operating time & Operation cycle \\
\hline Business area & 26,20 & $9: 30 \sim 21: 30$ & Every day \\
Catering area & 26,20 & $10: 00 \sim 21: 00$ & Every day \\
Office area & 26,22 & $7: 30 \sim 18: 00$ & Mon-Fri \\
Convention center & 26,22 & During usage & $1 \sim 2$ days a week \\
\hline
\end{tabular}

TABLE 3: System operation arrangement.

\begin{tabular}{lccc}
\hline Functional partition & Maximum personnel density $\left(\right.$ person $\left./ \mathrm{m}^{2}\right)$ & Lighting power density $\left(\mathrm{W} / \mathrm{m}^{2}\right)$ & Equipment power density $\left(\mathrm{W} / \mathrm{m}^{2}\right)$ \\
\hline Business area & 0.3 & 15 & 12 \\
Catering area & 0.33 & 14 & 8 \\
Office area & 0.25 & 12 & 15 \\
Convention center & 0.4 & 12 & 8 \\
\hline
\end{tabular}

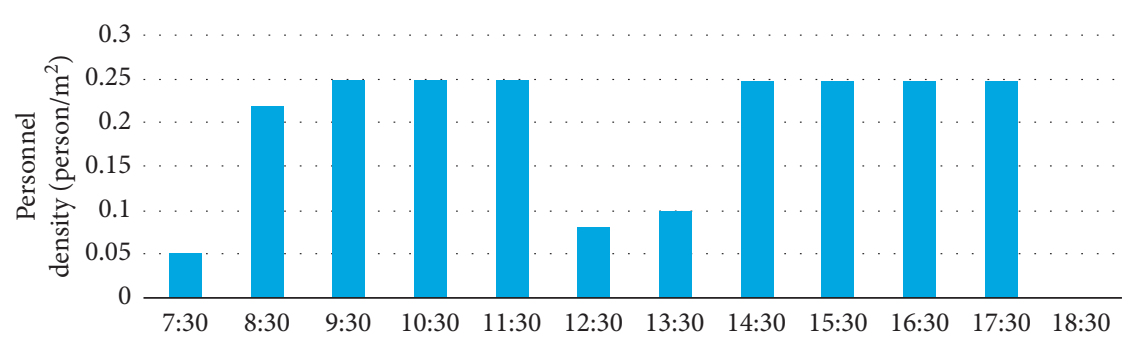

Figure 5: Dynamic change in the staff density in the office area.

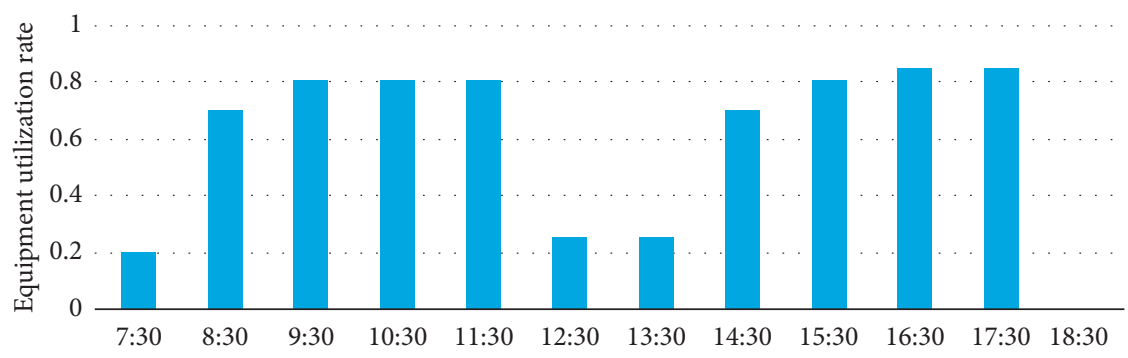

FIgURE 6: Dynamic change in equipment utilization in the office area.

TABLE 4: Comparison between the building monthly energy consumption simulation value and the actual value.

\begin{tabular}{|c|c|c|c|c|c|c|c|c|c|c|c|c|c|}
\hline Month & Jan & Feb & Mar & Apr & May & Jun & Jul & Aug & Sep & Oct & Nov & Dec & Jan-Dec \\
\hline Simulation value (MWh) & 465.19 & 368.07 & 146.43 & 151.46 & 197.14 & 334.13 & 479.70 & 462.79 & 302.22 & 156.79 & 146.23 & 349.50 & 3559.66 \\
\hline Actual value (MWh) & 480.10 & 352.22 & 155.24 & 164.26 & 212.75 & 350.17 & 514.16 & 489.53 & 326.15 & 148.56 & 154.67 & 364.82 & 3712.63 \\
\hline
\end{tabular}

longitudinal comparison of the different parameters. In the following section, DesignBuilder is used to simulate the building energy consumption when the six design parameters change and analyze and calculate its energy-saving potential.

4.1. Sensitivity Analysis of the Energy Savings of the External Wall Comprehensive Heat Transfer Coefficient. The comprehensive heat transfer coefficient of the external wall is an index used to measure the thermal insulation performance. The smaller its value is, the better the thermal insulation performance of the external wall is. Wuhan has hot-summer and cold-winter areas. The comprehensive heat transfer coefficient of the exterior wall of public buildings should not exceed 0.80 . In this section, the exterior wall construction in the reference model is taken as the benchmark scheme for the energy-saving sensitivity analysis, and the comprehensive heat transfer coefficient of the external wall is $0.50 \mathrm{~W} /$ $\left(\mathrm{m}^{2} \cdot \mathrm{K}\right)$. By taking $\pm 20, \pm 40, \pm 60 \%$ of the comprehensive heat transfer coefficient of the external wall in the standard scheme as the variation range, and modifying the thickness of the insulation layer of the external wall, the comprehensive heat transfer coefficient of the external wall varies uniformly between 0.20 and $0.80 \mathrm{~W} /\left(\mathrm{m}^{2} \cdot \mathrm{K}\right)$ and $0.10 \mathrm{~W} /$ $\left(\mathrm{m}^{2} \cdot \mathrm{K}\right)$. DesignBuilder software is used to analyze and 


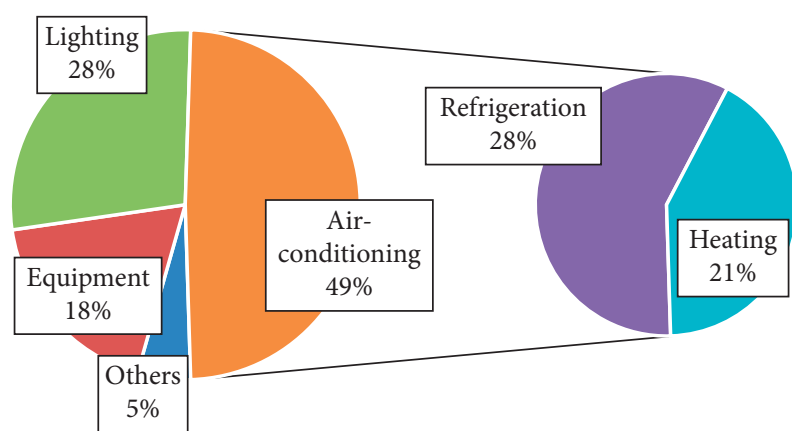

Figure 7: Percentage distribution of the building energy consumption.

calculate the energy-saving sensitivity of the comprehensive heat transfer coefficient of the external wall, as shown in Table 5.

According to the simulation results, the change in building energy consumption as a function of the comprehensive heat transfer coefficients of different external walls and the change trend diagram of the energy-saving ratio and sensitivity coefficient relative to the benchmark model are drawn, as shown in Figures 8 and 9, respectively. The analysis results are as follows.

(1) During the process of decreasing the comprehensive heat transfer coefficient of the external wall from $0.80 /\left(\mathrm{m}^{2} \cdot \mathrm{K}\right)$ to $0.20 \mathrm{~W} /\left(\mathrm{m}^{2} \cdot \mathrm{K}\right)$, the refrigeration energy consumption of the buildings shows a slightly increasing trend. The overall fluctuation is not large, the heating energy consumption is significantly reduced, and the total energy consumption of the whole year is significantly reduced. The decrease in the comprehensive heat transfer coefficient of the exterior wall means that the thermal insulation performance of the exterior wall is improved, and the heat transfer through the exterior wall can be better prevented during winter to reduce both the heat load caused by indoor heat dissipation and heating energy consumption. However, during summer, the thermal insulation performance of the external wall will reduce the heat transfer from the exterior wall to the outside at night, and the heat will be kept indoors. This heat load will lead to an increase in the building cooling load, so the cooling energy consumption of the building will slightly increase. When the comprehensive heat transfer coefficient of the exterior wall is reduced by $0.10 \mathrm{~W} /\left(\mathrm{m}^{2} \cdot \mathrm{K}\right)$, the total energy consumption of the buildings decreases by 7-8 Mwh, and the energy-saving rate increases by approximately $0.2 \%$. Therefore, the smaller the overall heat transfer coefficient of public buildings in the hot summer and cold winter is, the better the energysaving effect will be. Increasing the thickness of the thermal insulation layer and reducing the comprehensive heat transfer coefficient of the external wall are conducive to reducing the total energy consumption of buildings throughout the year and achieving the purpose of energy savings.
(2) The comprehensive heat transfer coefficient of the external wall has high-energy-saving sensitivity. According to Table 5, during the process of reducing the comprehensive heat transfer coefficient of the external wall, the sensitivity coefficient of the building total energy consumption to its change first decreases from 0.0106 to 0.0099 and then increases to 0.0120. That is, in the process of decreasing the comprehensive heat transfer coefficient from $0.8 \mathrm{~W} /$ $\left(\mathrm{m}^{2} \cdot \mathrm{K}\right)$ to $0.5 \mathrm{~W} /\left(\mathrm{m}^{2} \cdot \mathrm{K}\right)$ and then to $0.2 \mathrm{~W} /\left(\mathrm{m}^{2} \cdot \mathrm{K}\right)$, the energy savings of the building caused by a unit reduction of the comprehensive heat transfer coefficient of the external wall shows first decreases and then increases. Specifically, after reducing the comprehensive heat transfer coefficient of the external wall to below $0.5 \mathrm{~W} /\left(\mathrm{m}^{2} \cdot \mathrm{K}\right)$, the speed of reducing the total energy consumption of the building is accelerated. Therefore, from the perspective of the sensitivity coefficient, the comprehensive heat transfer coefficient of the external wall, which is conducive to energy savings, ranges from $0.5 \mathrm{~W} /$ $\left(\mathrm{m}^{2} \cdot \mathrm{K}\right)$ to below.

4.2. Sensitivity Analysis of the Design Parameters of the Building Envelope. In this section, taking the Wuhan region, which is located in a hot-summer and cold-winter climate zone, as an example, energy-saving sensitivity analysis is carried out for the main design parameters of the building envelope, namely, the external wall, roof, and external window. On the basis of the benchmark model, a set of variation values are set for each of the six design parameters of the building envelope. The energy consumption of large public buildings is simulated by DesignBuilder, and the energy-saving rate and the sensitivity coefficient of the parameters are calculated according to the simulation results. Due to the limited space of this paper, a detailed energy-saving sensitivity analysis of only the external wall comprehensive heat transfer coefficient is listed. The results of the analyses of the other five design parameters and the recommendations for the logarithms are given in Table 6.

According to the average value of the sensitivity coefficient, the parameters are sorted in the following order: the airtightness of the outer window, the ratio of the window to the wall, the comprehensive heat transfer coefficient of the exterior wall, the solar heat coefficient of the outer window, the comprehensive heat transfer coefficient of the external wall, and the comprehensive heat transfer coefficient of the roof. The airtightness of the outer window, the ratio of the window to the wall, and the comprehensive heat transfer coefficient of the exterior wall should be the key points of the next energy-saving optimization scheme of the building envelope. The average value of the sensitivity coefficient of the comprehensive heat transfer coefficient of the roof is only 0.0011 , indicating that the change has little impact on the building energy consumption. Therefore, the value can meet the requirements of the specification, which is not optimized under the existing conditions. The solar heat coefficient of the outer window and the comprehensive heat 
TABLE 5: Sensitivity of the external wall heat transfer coefficient to the total building energy consumption.

\begin{tabular}{|c|c|c|c|c|c|}
\hline $\begin{array}{l}\text { Scheme } \\
\text { number }\end{array}$ & $\begin{array}{l}\text { Comprehensive heat transfer coefficient } \\
\text { of the exterior wall }\left(\mathrm{W} /\left(\mathrm{m}^{2} \cdot \mathrm{K}\right)\right)\end{array}$ & $\begin{array}{l}\text { Total building energy } \\
\text { consumption (MWh) }\end{array}$ & $\begin{array}{l}\text { Energy saving of total } \\
\text { energy consumption (MWh) }\end{array}$ & $\begin{array}{c}\text { Energy- } \\
\text { saving } \\
\text { ratio (\%) }\end{array}$ & $\begin{array}{l}\text { Sensitivity } \\
\text { coefficient }\end{array}$ \\
\hline WA1 & 0.80 & 3582.33 & -22.72 & -0.638 & 0.0106 \\
\hline WA2 & 0.70 & 3574.51 & -14.89 & -0.418 & 0.0105 \\
\hline WA3 & 0.60 & 3566.66 & -7.05 & -0.198 & 0.0099 \\
\hline Base & 0.50 & 3559.62 & 0 & 0 & - \\
\hline WA5 & 0.40 & 3551.49 & 8.13 & 0.228 & 0.0114 \\
\hline WA5 & 0.30 & 3542.89 & 16.73 & 0.470 & 0.0118 \\
\hline WA6 & 0.20 & 3533.97 & 25.65 & 0.721 & 0.0120 \\
\hline
\end{tabular}

Note. The base represents the benchmark scheme. Sensitivity analysis scheme for energy saving of the external wall comprehensive heat transfer coefficient expressed by WA1-6.

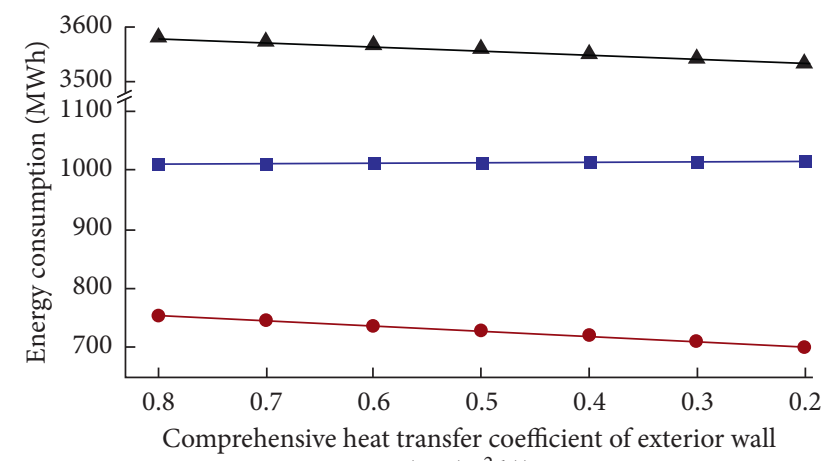

$\left(\mathrm{W} /\left(\mathrm{m}^{2} \cdot \mathrm{k}\right)\right)$

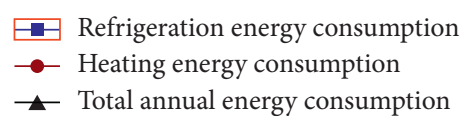

FIGURE 8: Variation in the building energy consumption when the comprehensive heat transfer coefficient of the external wall changes.

transfer coefficient of the external wall have a significant influence on the building energy consumption and should also be considered in the design of the optimization schemes.

\section{Analysis of the Energy-Saving Optimization Scheme of the Public Building Envelope}

Referring to the suggestions of the sensitivity analysis of energy conservation in the previous section, this section proposes corresponding optimization schemes for the design parameters of the five envelope structures, except for the comprehensive heat transfer coefficient of the roof.

\subsection{Determination of the Factor Level in the Orthogonal} Experiment. To reduce the number of simulations and take into account the influence of each parameter on building energy consumption, this paper adopts the method of orthogonal experimental design. This approach takes the above five factors (besides the comprehensive heat transfer coefficient of the roof) as the factors of the orthogonal experiment, choosing three levels for each factor, arranging experiments with an orthogonal table, and passing a few generations. Experiments were conducted to analyze the effects of the various levels of factors on the results, and combined with economic factors and practical experience, the optimal combination of energy-saving optimization schemes is finally determined, as shown in Table 7.

5.1.1. External Wall Structure. The structure of the external wall determines the comprehensive heat transfer coefficient of the external wall. The analysis of Section 4.1 concludes that the comprehensive heat transfer coefficient of the exterior wall of public buildings in hot-summer and coldwinter areas is $0.5 \mathrm{~W} /\left(\mathrm{m}^{2} \cdot \mathrm{K}\right)$ and below, which can achieve a better energy-saving effect. This section takes the external wall structure in the benchmark model as the basic structure, that is, $13 \mathrm{~mm}$ decorative brick $+20 \mathrm{~mm}$ lime morta $+10 \mathrm{~mm}$ expanded polystyrene (EPS) insulation $+240 \mathrm{~mm}$ aerated concrete $+20 \mathrm{~mm}$ lime mortar. The comprehensive heat transfer coefficient of the external wall is changed by changing the thickness of the insulation. The external wall structure of $10 \mathrm{~mm}, 30 \mathrm{~mm}$, and $50 \mathrm{~mm}$ thick EPS insulation is selected as the three levels of factors, and the corresponding external wall comprehensive heat transfer coefficient is $0.5 \mathrm{~W} /\left(\mathrm{m}^{2} \cdot \mathrm{K}\right), 0.404 \mathrm{~W} /\left(\mathrm{m}^{2} \cdot \mathrm{K}\right)$, and $0.336 \mathrm{~W} /$ $\left(\mathrm{m}^{2} \cdot \mathrm{K}\right)$, respectively.

5.1.2. External Window Type. The external window includes a glass type and a window frame type, which have an effect on the comprehensive heat transfer coefficient and solar heat coefficient of the external window. Common energy-saving technologies of window frames are broken aluminum alloy window frames, plastic window frames (poly (vinyl chloride), PVC), glass frames, and compound window frames. The plastic and steel window frame has advantages of a low heat transfer coefficient, low production energy consumption, and long-term economic and social benefits. Therefore, the plastic and steel window frame is selected as part of the external window optimization scheme.

The overall heat transfer performance of the outer window depends mainly on the heat transfer performance of the glass. At present, the most widely used energy-saving glass technologies are hollow glass, coated glass, and low emissivity (low-e) glass. The hollow layer of the hollow glass can be filled with inert gas instead of air for better insulation. The commonly used inert gas is argon. Low-e glass is a type of coated glass with a high transmittance of near infrared 


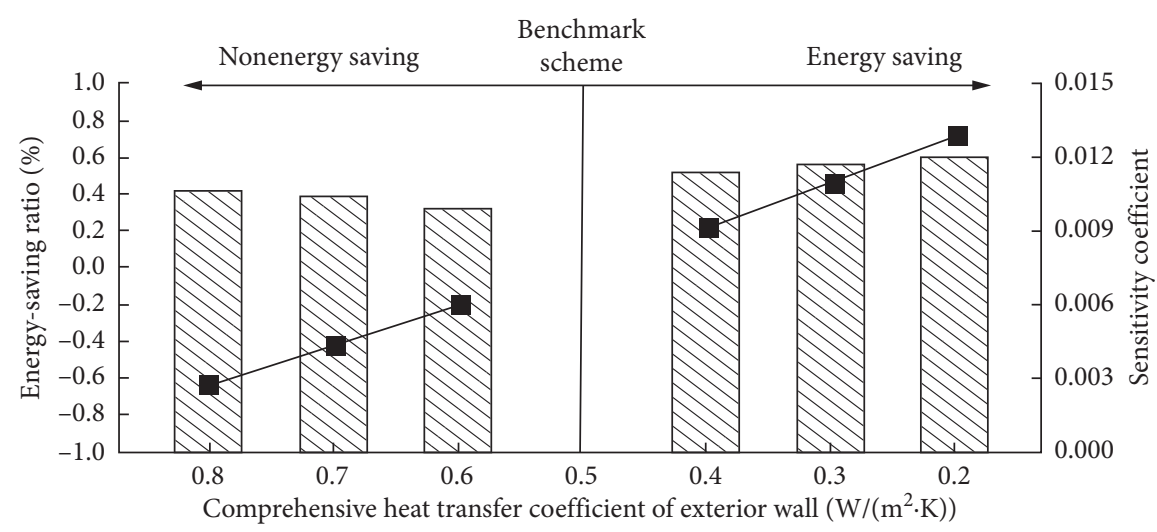

Energy-saving ratio

Sensitivity coefficient

FIGURE 9: Energy-saving ratio and energy-saving sensitivity of the comprehensive heat transfer coefficient of the external wall.

TABLE 6: Design parameters of the building envelope energy-saving potential sequencing and recommended values.

\begin{tabular}{|c|c|c|c|c|c|}
\hline \multirow{2}{*}{ Design parameters of building envelope } & \multicolumn{3}{|c|}{ Sensitivity coefficient } & \multirow{2}{*}{ Sorting } & \multirow{2}{*}{ Recommended values } \\
\hline & Maximum & Minimum & Average & & \\
\hline $\begin{array}{l}\text { The comprehensive heat transfer coefficient of } \\
\text { the exterior wall }\end{array}$ & 0.0120 & 0.0099 & 0.0111 & 5 & $\leq 0.5 \mathrm{~W} /\left(\mathrm{m}^{2} \cdot \mathrm{K}\right)$ \\
\hline $\begin{array}{l}\text { The comprehensive heat transfer coefficient of } \\
\text { the roof }\end{array}$ & 0.0013 & 0.0009 & 0.0011 & 6 & As small as possible, if the criterion is met \\
\hline $\begin{array}{l}\text { The comprehensive heat transfer coefficient of } \\
\text { the external windows }\end{array}$ & 0.0385 & 0.0318 & 0.0352 & 3 & As small as possible, if the criterion is met \\
\hline The solar heat coefficient of the outer window & 0.0207 & 0.0118 & 0.0166 & 4 & $0.3795 \mathrm{~W} /\left(\mathrm{m}^{2} \cdot \mathrm{K}\right) \sim 0.44 \mathrm{~W} /\left(\mathrm{m}^{2} \cdot \mathrm{K}\right)$ \\
\hline The ratio of the window to the wall & 0.0481 & 0.0354 & 0.0416 & 2 & As small as possible, if the functionality is met \\
\hline The airtightness of the outer window & 0.0496 & 0.0457 & 0.0474 & 1 & $\begin{array}{l}\text { The higher the level is, the more feasible the } \\
\text { technology and economy are. The } \\
\text { recommendation is above level } 4\end{array}$ \\
\hline
\end{tabular}

TAвLE 7: Orthogonal test factor level table.

\begin{tabular}{|c|c|c|c|}
\hline Factor & Level 1 & Level 2 & Level 3 \\
\hline External wall structure & $10 \mathrm{~mm}$ & $30 \mathrm{~mm}$ & $50 \mathrm{~mm}$ \\
\hline External window type B & $\begin{array}{c}\text { Plastic steel window } \\
\text { frame }+3 \mathrm{~mm} \text { white glass } \\
\text { coating }+13 \mathrm{~mm} \text { air }+3 \mathrm{~mm} \text { white } \\
\text { glass }\end{array}$ & $\begin{array}{c}\text { Plastic steel window } \\
\text { frame }+6 \mathrm{~mm} \text { white glass } \\
\text { coating }+6 \mathrm{~mm} \text { air }+6 \mathrm{~mm} \text { white } \\
\text { glass }\end{array}$ & $\begin{array}{c}\text { Plastic steel window } \\
\text { frame }+6 \mathrm{~mm} \text { white glass } \\
\text { coating }+13 \mathrm{~mm} \text { air }+6 \mathrm{~mm} \text { white } \\
\text { glass }\end{array}$ \\
\hline Shade type C & $\begin{array}{l}0.5 \mathrm{~mm} \text { horizontal outside } \\
\text { shading }\end{array}$ & $\begin{array}{c}0.8 \mathrm{~mm} \text { horizontal outside } \\
\text { shading }\end{array}$ & $\begin{array}{l}1.0 \mathrm{~mm} \text { horizontal outside } \\
\text { shading }\end{array}$ \\
\hline $\begin{array}{l}\text { The ratio of the window to wall } \\
\text { D }\end{array}$ & $25 \%$ & $30 \%$ & $35 \%$ \\
\hline Airtightness E & Level 3 & Level 4 & Level 5 \\
\hline
\end{tabular}

rays and a high reflectivity of far infrared rays. This type of glass can reduce heat loss, especially in cold areas. In this paper, the selected insulating glass and insulating glass combined with coated glass are shown in Table 7 . The comprehensive heat transfer coefficients of the three horizontal external windows are $2.976 \mathrm{~W} /\left(\mathrm{m}^{2} \cdot \mathrm{K}\right), 2.722 \mathrm{~W} /$ $\left(\mathrm{m}^{2} \cdot \mathrm{K}\right)$, and $2.283 \mathrm{~W} /\left(\mathrm{m}^{2} \cdot \mathrm{K}\right)$.

5.1.3. Shade Type. An external window shade can directly block the sunlight to the indoors, reduce the heat of the sunlight entering the room, and improve the thermal environment inside the room in summer. According to the relative position of sunshade facilities and windows, sunshades can be classified into three types: external shading, inner shading, and double glass middle shading. The shading effect of internal shade and middle shading is better, but the location of both determines that the shading facility itself can absorb some heat easily and transfer it indoors. The heat absorbed by external shading itself is removed through air flow and will not produce an indoor load. A comprehensive sunshade is better. In this section, a horizontal outside shade board is chosen. 
TABLE 8: Orthogonal experimental design and factor visual analysis of the public building envelope optimization.

\begin{tabular}{|c|c|c|c|c|c|c|}
\hline \multirow[b]{2}{*}{ Test number } & \multicolumn{5}{|c|}{ Factor level } & \multirow{2}{*}{$\begin{array}{l}\text { Total building energy } \\
\text { consumption }\end{array}$} \\
\hline & External wall structure a & $\begin{array}{c}\text { External window } \\
\text { type B }\end{array}$ & Shade type C & $\begin{array}{l}\text { The ratio of the } \\
\text { window to wall } \mathrm{D}\end{array}$ & Airtightness E & \\
\hline 1 & 1 & 1 & 1 & 1 & 1 & 3450.128 \\
\hline 2 & 1 & 2 & 2 & 2 & 2 & 3426.089 \\
\hline 3 & 1 & 3 & 3 & 3 & 3 & 3350.057 \\
\hline 4 & 2 & 1 & 1 & 2 & 2 & 3410.911 \\
\hline 5 & 2 & 2 & 2 & 3 & 3 & 3402.667 \\
\hline 6 & 2 & 3 & 3 & 1 & 1 & 3388.387 \\
\hline 7 & 3 & 1 & 2 & 1 & 3 & 3370.344 \\
\hline 8 & 3 & 2 & 3 & 2 & 1 & 3440.368 \\
\hline 9 & 3 & 3 & 1 & 3 & 2 & 3367.542 \\
\hline 10 & 1 & 1 & 3 & 3 & 2 & 3448.943 \\
\hline 11 & 1 & 2 & 1 & 1 & 3 & 3382.28 \\
\hline 12 & 1 & 3 & 2 & 2 & 1 & 3406.409 \\
\hline 13 & 2 & 1 & 2 & 3 & 1 & 3471.258 \\
\hline 14 & 2 & 2 & 3 & 1 & 2 & 3440.64 \\
\hline 15 & 2 & 3 & 1 & 2 & 3 & 3333.383 \\
\hline 16 & 3 & 1 & 3 & 2 & 3 & 3388.186 \\
\hline 17 & 3 & 2 & 1 & 3 & 1 & 3460.433 \\
\hline 18 & 3 & 3 & 2 & 1 & 2 & 3347.98 \\
\hline $\bar{T}_{1}$ & 3410.651 & 3423.295 & 3400.779 & 3396.627 & 3436.164 & \\
\hline $\bar{T}_{2}^{1}$ & 3407.874 & 3425.413 & 3404.124 & 3400.891 & 3407.017 & \\
\hline $\bar{T}_{3}^{2}$ & 3395.809 & 3365.626 & 3409.430 & 3416.817 & 3371.153 & \\
\hline$R$ & 14.842 & 59.787 & 8.651 & 20.190 & 65.011 & \\
\hline
\end{tabular}

5.1.4. Ratio of the Window to the Wall. The conclusion of the preceding analysis is that the smaller the window-to-wall ratio of the public buildings in the hot-summer and coldwinter areas is, the lower the energy consumption is. However, due utilization needs, the effect of an increase or a decrease in the external window area on the indoor natural lighting is considered. The "Code for Design of Office Buildings" stipulates that the window-to-floor ratio of offices should not be less than $1 / 5$ and that of corridors, stairwells, and bathrooms should not be less than $1 / 12$. The main building studied in this paper is an office building. Taking a standard office floor as an example, in an office area, the area near the window is estimated to be $596 \mathrm{~m}^{2}$, and the area of the walkway is estimated to be $120 \mathrm{~m}^{2}$. Based on these dimensions, the area of the building outside the window should be no less than $131 \mathrm{~m}^{2}$, and the ratio of the window to wall should be no less than $24 \%$. Therefore, the 3 levels of the window-to-wall ratio are determined to be $25 \%, 30 \%$, and $35 \%$.

5.1.5. Airtightness. Among the 6 design parameters of the building envelope analyzed in Section 4.2, the sensitivity of the building energy consumption external window airtightness is the highest. From the point of view of energy savings, the greater the airtightness level of the outer window is, the better the energy savings are. However, the cost of realizing a superior level of airtightness of the windows and doors is higher at the present technical level. From an economic point of view, the outer window with three, four, and five levels of airtightness is selected. The corresponding number of breaths is $0.30 \mathrm{ac} / \mathrm{h}, 0.25 \mathrm{ac} / \mathrm{h}$, and $0.20 \mathrm{ac} / \mathrm{h}$.
5.2. Orthogonal Experimental Design and Result Analysis. In this paper, the number of factors and the level of each factor are determined to be 5 and 3, respectively. The L18 (37) orthogonal table is used to design an orthogonal table, and DesignBuilder is used to simulate the building energy consumption level in 18 groups of experiments. The results are shown in Table 8 below. Among the selected schemes, the energy consumption of the fifteenth set of schemes $\mathrm{A} 2 \mathrm{~B} 3 \mathrm{C} 1 \mathrm{D} 2 \mathrm{E} 3$ is the lowest, and the annual total energy consumption is $3333.383 \mathrm{MWh}$.

5.2.1. Factor Range Analysis. The average value of each factor at each level is calculated as $\bar{T}_{q}(q=1,2,3$, which represent level 1 , level 2 , and level 3 , respectively), and the range $R$ of the effect of each factor level on the test results is calculated, as shown in Table 9. The factor range distribution of the orthogonal test for the envelope optimization of public buildings is shown in Figure 10.

By comparing the energy conservation potential ranking of the parameters in Tables 6 and 9, the comprehensive range and sensitivity analyses have determined that the airtightness, the exterior window type, and the window-to-wall ratio are the most important factors that affect the building energy consumption. Additionally, the exterior wall structure and shading type also have a certain impact on building energy consumption. Based on the results of the sensitivity analysis of energy conservation in the previous section, in this section, the corresponding optimization schemes for the design parameters of the five envelope structures are proposed, except for the comprehensive heat transfer coefficient of the roof. 
TABLE 9: Comparison between the factor range analysis and factor sensitivity analysis.

\begin{tabular}{|c|c|c|c|c|c|}
\hline $\begin{array}{l}\text { Factor/ } \\
\text { corresponding } \\
\text { parameter }\end{array}$ & $\begin{array}{l}\text { Airtightness/ } \\
\text { airtightness } \\
\text { of the external } \\
\text { window }\end{array}$ & $\begin{array}{c}\text { External window type/ } \\
\text { comprehensive heat transfer } \\
\text { coefficient of the external window }\end{array}$ & $\begin{array}{l}\text { The ratio of the window } \\
\text { to } \\
\text { wall/the ratio of the } \\
\text { window to wall }\end{array}$ & $\begin{array}{l}\text { External wall structure/ } \\
\text { comprehensive heat } \\
\text { transfer coefficient } \\
\text { of the external wall }\end{array}$ & $\begin{array}{c}\text { Shade type/ } \\
\text { outer } \\
\text { window } \\
\text { solar heat } \\
\text { coefficient }\end{array}$ \\
\hline Range $R$ sort & 1 & 2 & 3 & 4 & 5 \\
\hline Sensitivity sort & 1 & 3 & 2 & 5 & 4 \\
\hline
\end{tabular}

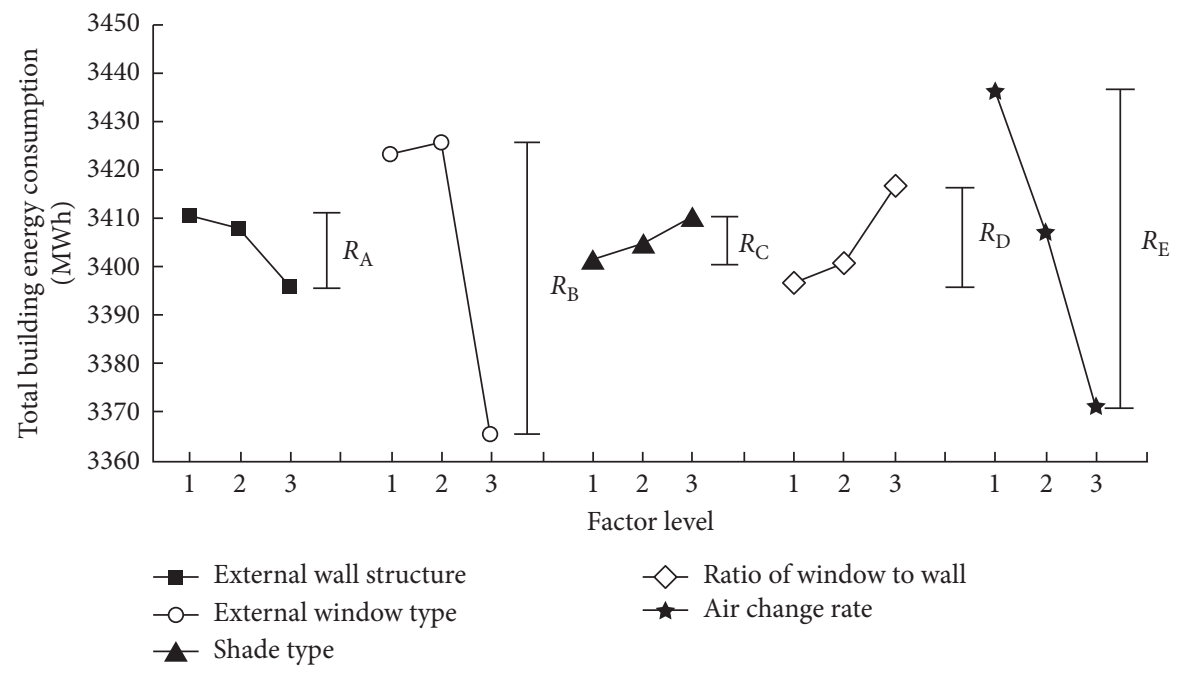

Figure 10: Influence of the different levels of the enclosure structure on the total building energy consumption in public buildings.

5.2.2. Factor Variance Analysis. According to the method in Section 2.4.2, the significant level of factors is chosen as 0.05, and the factor variance analysis is carried out by means of an "orthogonal design assistant." The results show that the type of window and airtightness are highly significant factors affecting building energy consumption. The ratio of the exterior wall structure to the window wall has a significant effect on building energy consumption, but the shade type does not. Therefore, the shading type can be chosen freely when the scheme is optimized.

5.2.3. Optimal Scheme Determination. The structure of the exterior wall, the type of exterior window, the ratio of the window to wall, and the airtightness significantly affect the building energy consumption. The lowest average energy consumption level should be chosen as the optimal scheme, namely, an exterior wall of $50 \mathrm{~mm}$ EPS insulation, a plastic steel window frame, and a $6 \mathrm{~mm}$ white glass coating $+13 \mathrm{~mm}$ air $+6 \mathrm{~mm}$ white glass window combination and a $25 \%$ window-to-wall ratio, and the airtightness grade is 5 for the outer window. The effect of the shading type on building energy consumption is not significant and can be determined freely. According to the range analysis, a horizontal shading with a $0.5 \mathrm{~m}$ width has the best shading effect and saves material compared with other schemes. Therefore, a $0.5 \mathrm{~m}$ wide horizontal shading is chosen as the shading scheme. Thus, the optimized scheme is A3B3C1D1E3.
The simulation results show that the total annual energy consumption of the optimal scheme is $336.06 \mathrm{MWh}$, which is lower than that of the orthogonal table. The optimal scheme is different from that of the orthogonal table, which reflects the advantage of the orthogonal experiment, i.e., finding the optimal result with the least number of experiments. Compared with the benchmark model, the total energy consumption of the whole year is reduced by 243.46 MWh, which fully shows that there is considerable energy-saving space for optimizing the envelope structure of public buildings in hot-summer and cold-winter areas.

\section{Conclusions}

In this paper, the energy consumption of public buildings is simulated by means of energy consumption simulations, and the sensitivity of common design parameters of the envelope structure is analyzed, which are regarded as the criteria of the energy-saving potential scheme. The key objects for program optimization are identified. On this basis, a feasible optimization scheme is proposed for each design parameter with a high-energy-saving potential, and the optimal scheme combination of the energy-saving effect is quickly analyzed using the orthogonal design method to arrange the test. The main tasks accomplished in this chapter are as follows.

Taking the large public buildings in Wuhan as an example, an energy consumption simulation model is established. The annual energy consumption of the buildings is simulated by DesignBuilder software, and the reliability of 
the model is verified. The verified model is the basis of further research.

Using the sensitivity analysis method, the energy-saving sensitivity analysis of the six main design parameters of the building envelope structure is carried out in turn. The sensitivity coefficient is depicted in the following order: airtightness of outer window $>$ ratio of the window to the wall $>$ comprehensive heat transfer coefficient of the outer window $>$ solar heat coefficient of the outer window> comprehensive heat transfer coefficient of the exterior wall $>$ comprehensive heat transfer coefficient of the roof. According to the results of the energy consumption simulation and sensitivity analysis, a suggested value range is proposed for each parameter. This range can be implemented according to the above order and can be suggested to optimize the envelope structure for energy saving.

The sensitivity of the comprehensive heat transfer coefficient of the roof is low, so the roof is not optimized in the optimization scheme of the enclosure structure. According to the other five factors, the optimization scheme is presented in turn, considering the mutual influence of each parameter on the building energy consumption and the orthogonal design.

Because of the vast territory of China, which spans five climatic zones, different climatic areas have different energy consumption needs, and in addition, different types of large public buildings have different characteristics of energy consumption among different types of public buildings. Therefore, the energy-saving potential of thermal engineering design parameters between different climatic regions and different types of large-scale public buildings should be considered in the follow-up study.

\section{Data Availability}

The data used to support the findings of this study are included within the article.

\section{Conflicts of Interest}

The authors declare that there are no conflicts of interest regarding the publication of this paper.

\section{Authors' Contributions}

Dr. Yang Liu designed and performed the experiment. Dr. Shiqing Zou converted all the TIFF, JPG, JPEG, and BMP formats into the editable figure files. Dr Hongyu Chen helped in English writing and optimized the format of this article. Dr. Xianguo Wu guided the research ideas. Dr. Wenman Chen adjusted the figures and tables according to Professor Giosuè Boscato's suggestion.

\section{Acknowledgments}

This is research was supported by the National Natural Science Foundation of China (nos. 71571078).

\section{References}

[1] https://www.bp.com/zh_cn/china/reports-and-publications/_ bp_2018-_.html.

[2] D. Yan, T. Hong, C. Li, Q. Zhang, J. An, and S. Hu, “A thorough assessment of China's standard for energy consumption of buildings," Energy and Buildings, vol. 143, pp. 114-128, 2017.

[3] T. Huo, H. Ren, X. Zhang et al., "China's energy consumption in the building sector: a statistical yearbook-energy balance sheet based splitting method," Journal of Cleaner Production, vol. 185, pp. 665-679, 2018.

[4] H. Ma, N. Du, S. Yu et al., "Analysis of typical public building energy consumption in northern China," Energy and Buildings, vol. 136, pp. 139-150, 2017.

[5] J. Hou, Y. Wu, and Y. S. Liu, "Research on market approaches to energy-saving reform of existing public buildings," Urban Development Research, vol. 21, no. 2, pp. 1-5, 2014.

[6] J. Zhao, X. Xie, R. Liu, Y. Sun, M. Wu, and J. Gu, "Water and energy saving potential by adopting pressure-reducing measures in high-rise building: a case analysis," Building Services Engineering Research and Technology, vol. 39, no. 5, pp. 505-517, 2018.

[7] M. E. Baran, N. Mahajan, and S. Teleke, "Simulation-based design of protection schemes for shipboard power systems," in Proceedings of the 2007 Summer Computer Simulation Conference, vol. 4, Society for Computer Simulation International, San Diego, CA, USA, 2007.

[8] S. Zhou and J. Zhao, "Optimum combinations of building envelop energy-saving technologies for office buildings in different climatic regions of China," Energy and Buildings, vol. 57, no. 2, pp. 103-109, 2013.

[9] L. Shi, H. Zhang, Z. Li, Z. Luo, and J. Liu, "Optimizing the thermal performance of building envelopes for energy saving in underground office buildings in various climates of China," Tunnelling and Underground Space Technology, vol. 77, pp. 26-35, 2018.

[10] M. O. B. C. Melo, L. B. da Silva, A. S. Coutinho, V. Sousa, N. Perazzo, and N. Perazzo, "Energy efficiency in building installations using thermal insulating materials in northeast Brazil," Energy and Buildings, vol. 47, pp. 35-43, 2012.

[11] A. Antonyová, A. Korjenic, P. Antony et al., "Hygrothermal properties of building envelopes: reliability of the effectiveness of energy saving," Energy and Buildings, vol. 57, pp. 187-192, 2013.

[12] J. Huang, H. Lv, T. Gao, W. Feng, Y. Chen, and T. Zhou, "Thermal properties optimization of envelope in energysaving renovation of existing public buildings," Energy and Buildings, vol. 75, pp. 504-510, 2014.

[13] L. Zhang, "Simulation analysis of built environment based on design builder software," Applied Mechanics and Materials, vol. 580-583, pp. 3134-3137, 2014.

[14] J. R. New, "Suitability of ASHRAE guideline 14 metrics for calibration," Ashrae Transactions, Atlanta, GA, USA, 2016.

[15] S. Anna and H. Foit, "Sensitivity analysis of the proposed method for determining dynamic heat flux lost through the building envelope," in Proceedings of the International Conference environmental Engineering 2014, Vilnius, Lithuania, 2014.

[16] J. Zhu, D. A. S. Chew, S. Lv, and W. Wu, “Optimization method for building envelope design to minimize carbon emissions of building operational energy consumption using orthogonal experimental design (OED)," Habitat International, vol. 37, pp. 148-154, 2013. 


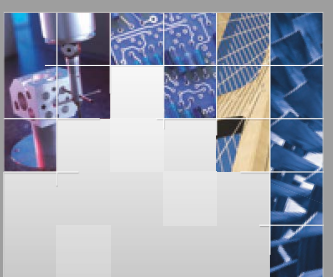

\section{Enfincering}
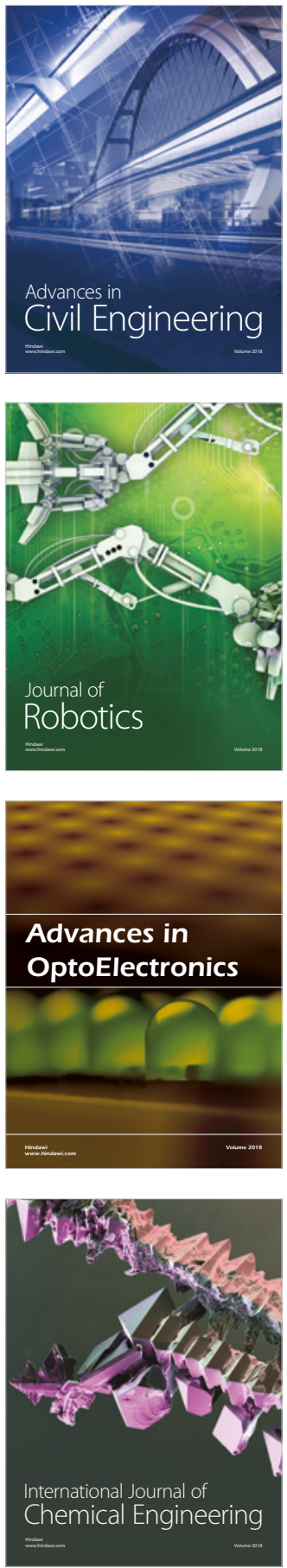

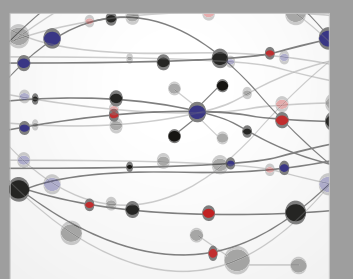

\section{Rotating \\ Machinery}

The Scientific World Journal

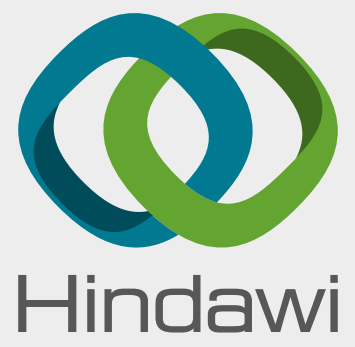

Submit your manuscripts at

www.hindawi.com
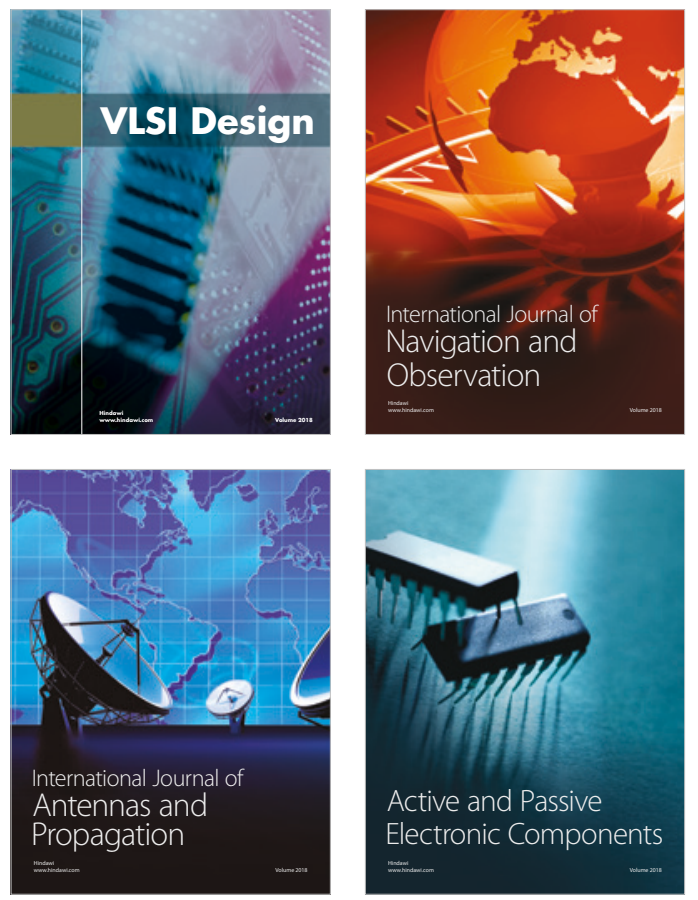
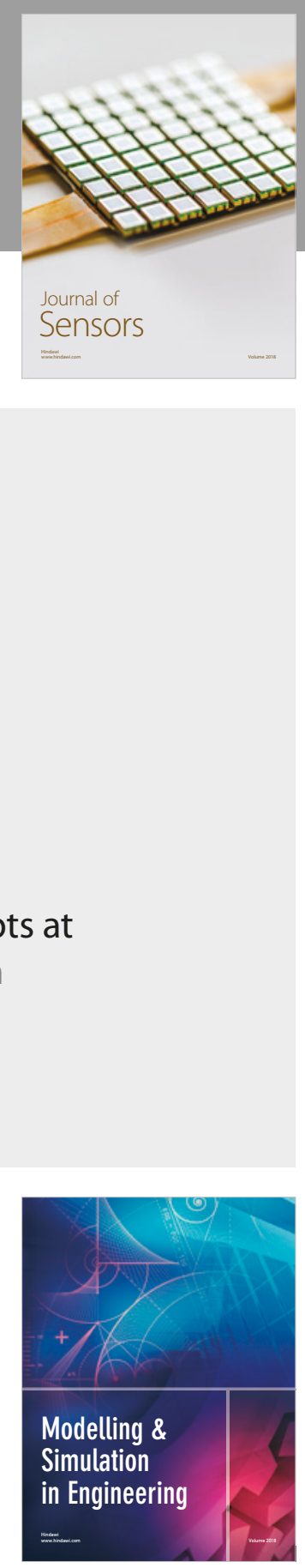

\section{Advances \\ Multimedia}
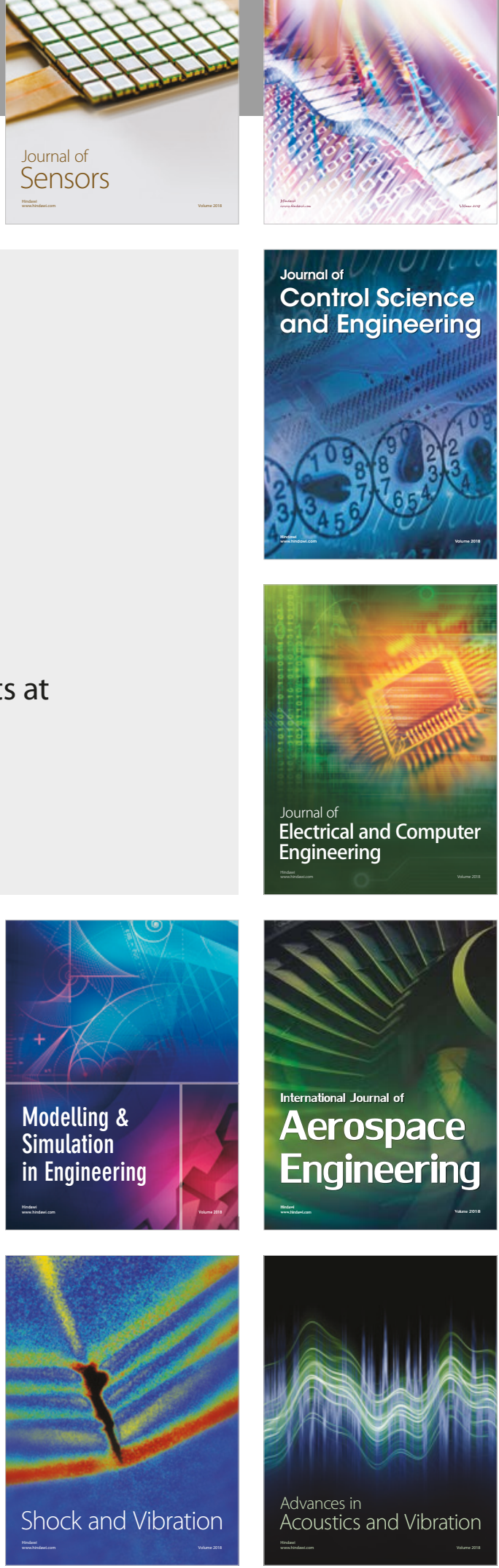